\title{
Perception and memory of orientation of forms by young readers
}

\author{
DOREEN ASSO, SAFIA MAGDI and MARIA A. WYKE \\ National Hospital, Maida Vale, London, England
}

\begin{abstract}
This paper describes a study designed to establish whether young readers (15 boys, 15 girls, 10 to 11 years of age) are able to match and remember the spatial orientation of simple forms as proficiently as they can match and remember spatially confusable letters, i.e., letters whose differential features depend upon their spatial orientation: $p, q, d, b, u, n$, and, to a lesser extent, $h$ and $y, w$ and $m$. The results show that the ability of young readers to match the spatial orientation of forms is not significantly inferior to their accuracy in matching spatially confusable letters. On the other hand, their ability to remember the spatial orientation of forms is significantly inferior to their accuracy in remembering spatially confusable letters. The results also indicate that there is no correlation between individual performances in a reading test and the test which required the subject to remember the spatial orientation of forms. Analysis of the type of errors made in the latter test indicates that the most prevalent error is that of confusing a form with its left-right reversal. Some theoretical implications of the findings are discussed.
\end{abstract}

This paper describes a study designed to test the ability of young readers to match and recognize the orientation of spatially confusable letters and of simple forms. The term "spatially confusable letters" (Asso \& Wyke, 1971) refers to those letters whose differential features depend upon their spatial orientation; that is to say, the letters $\mathrm{p}, \mathrm{q}, \mathrm{d}, \mathrm{b}, \mathrm{u}$ and $\mathrm{n}$, and to a lesser extent $\mathrm{h}$ and $\mathrm{y}$ and $\mathrm{w}$ and $\mathrm{m}$.

There are several studies (Davidson, 1935; Gibson, Gibson, Pick, \& Osser, 1962; Hildreth, 1932; Ilg \& Ames, 1950; Wilson \& Fleming, 1938), indicating that discrimination of spatially confusable letters presents specific difficulty to all children; and it is not until the age of 8 years that children can accurately discriminate the different orientation of such letters. This finding has been variously interpreted as being the result of a deficit in the child's ability to attend to, perceive, or to memorize spatial orientation. Most theories (see Fellows, 1968) have accounted in a similar way for the cognitive process involved in both the discrimination and recognition of confusable letters and the discrimination and recognition of the spatial orientation of forms in general.

This interpretation has gained support from reports (Lovell, Shapton, \& Warren, 1964; Lyle, 1969; Shepherd, 1956; Vernon, 1957; Wechsler \& Hagin, 1964) claiming that the tendency of children with reading problems to rotate and to reverse letters while reading is associated with a concomitant defect in the discrimination and memory of the spatial orientation of other forms. However, in order to substantiate the notion that the same cognitive process underlies both

We thank the Inner London Education Authority, the Headmaster and staff of the Reay School, London, S.W.9, and the Institute of Neurology, Queen Square, London, for facilities provided, also Dr. R. T. C. Pratt for his comments on the manuscript. We are grateful to J. Edwards for preparation of the figures. Doreen Asso is at Goldsmiths' College, University of London. Robert Sekuler sponsors this paper and takes full editorial responsibility for it. abilities, it would be necessary to show that children who have learned to read adequately and make no errors in identifying confusable letters have also learned to discriminate and to recognize spatial orientation of forms in general. Clear evidence of this sort is lacking, although this is an important point of practical as well as theoretical significance.

The present investigation was undertaken to establish whether young readers are able to match and to remember the spatial orientation of simple forms as proficiently as they can match and remember spatially confusable letters.

\section{METHOD}

The subjects were 30 English children ( 15 boys and 15 girls) whose ages ranged from 10 years to 11 years 7 months (mean age 10 years 7 months); all the children were rated by their teachers as "average" in their school performance, and were attending the same school. Their reading ages (Schonell \& Schonell, 1956) ranged from 9 years 6 months to 12 years 6 months (mean age 10 years 8 months). There was little discrepancy between reading and chronological age, except for one subject whose reading age was 10 months below and another whose reading age was 17 months above the chronological age.

\section{Test Material}

The test material consisted of (1) Ten spatially confusable letters (shown in Figure 1, top row) of the simple type in customary use in primary schools, drawn in black ink in lower case. The letters $\mathrm{w}$ and $\mathrm{y}$ were drawn as reversals of the letters $\mathrm{m}$ and $h$, respectively. Ten other letters (see Figure 1, bottom row), most likely to be confused with the experimental letters, were also used. These letters were selected on the basis of their similarity with the spatially confusable letters as follows-the letters $\mathrm{g}, \mathrm{t}, \mathrm{j}, \mathrm{l}$, and $\mathrm{f}$ were regarded as being similar to the letters $\mathrm{b}, \mathrm{d}, \mathrm{p}, \mathrm{q}, \mathrm{y}$, and $\mathrm{h}$, because in both groups of letters the principal feature is the presence of a long central line. The letters $\mathrm{a}, \mathrm{c}, \mathrm{e}, \mathrm{o}$, and $\mathrm{s}$ were regarded as being basically similar to the letters $\mathrm{n}, \mathrm{u}, \mathrm{m}$, and $\mathrm{w}$ because of their short curvilinear characteristics. The rationale of this selection procedure is supported by the results of factorial analysis of the similarities 
b $\quad d \quad p \quad q \quad n \quad u \quad m \quad m \quad h \quad 4$

a c e $\quad$ e $\quad g \quad j \quad l \quad o$ s $t$

Figure 1. Letters used in the test.

between lower-case letters of the English alphabet (see Dunn-Rankin, 1968). (2) Also there were ten asymmetrical forms (shown in Figure 2). Eight of these forms were based on Arabic characters while the remaining two (see Figure 2, Rows 2 and 8 ) were taken from the "letter-like" forms designed by Gibson et al. (1962). These forms were chosen because they are known to be easily discriminated by young children.

\section{Procedure}

The discrimination of letters and forms was performed by each child using two methods: simultaneous presentation of standard and choice cards and successive presentation of standard and choice cards.

The simultaneous presentation tests (letters) required the subject to match a spatially confusable letter with an identical one in the following manner: each spatially confusable letter from the array in Figure 1 was presented above a strip of paper on which a row of 1 -in. square boxes was drawn, each of which contained a different letter. The number of letters with which the standard could be matched was 11 in the case of the "long" letters (comprising $p, q, b, d, y, h, g, t, j, 1, f$ ) and 9 in the case of "short" letters (comprising n, u, m, w, a, c, e, o, s). In cach set of

Figure 2. Standard forms and their transformations. Ro equals Rotation; Re equals Reversal; $L$ equals Left; $R$ equals Right; $U$ equals Up; $D$ equals Down; $D_{1}, D_{2}$ equal Distortions. letters presented, there was only one that was identical with the standard letter.

For each of the 10 confusable letters there were two paper strips each of which contained a different random array of letters from which the matching letter could be selected. The subject was asked to look at the array of letters on each of the 20 paper strips (presented in random order) and point to the letter that exactly matched the standard.

A similar procedure was carried out with the forms; the subjects being asked to match each standard form with an identical form. In this instance the choice had to be made from eight possible alternatives which included (besides the standard) two rotations $(90-\mathrm{deg}$ to the left and 90 -deg to the right), three reversals (left-right, up-down, and up-down and left-right) and two distortions (i.e., approximation to the shape of the standard). The standard forms and their transformation are shown in Figure 2. Orientational differences were defined in terms of transformations of axes using the criteria proposed by Fellows (1968). For each of the 10 forms, there were two paper strips, each of which contained a different random array of test forms from which the matching form could be selected. The instructions were similar to those given in the test of matching letters.

In the successive presentation test a letter or form was shown tachistoscopically to the subjects at the center of their field of vision, with exposure times for both letters and forms of $100 \mathrm{msec}$. It was previously established that a 100-msec exposure was sufficient to enable the subjects to perceive adequately both the letters and forms. Immediately after presentation of the standard the subjects were asked to look at the strip of paper (the same as in the matching task) and to point to the letter or form that was exactly like the standard. A brief training session was provided for each subject.

\begin{tabular}{|c|c|c|c|c|c|c|c|}
\hline $\begin{array}{l}\text { Stand- } \\
\text { ard }\end{array}$ & $\begin{array}{r}90^{\circ} \\
R O . R\end{array}$ & $\begin{array}{r}90^{\circ} \\
\text { Ro.L }\end{array}$ & $\begin{array}{l}\text { L-R } \\
\text { Re. }\end{array}$ & $\begin{array}{l}U-D \\
\text { Re. }\end{array}$ & $\begin{array}{c}\text { U.D/L.R } \\
\mathrm{Re} .\end{array}$ & $D$ & $D$ \\
\hline$v$ & C & 3 & $u$ & $\Omega$ & $\Omega$ & $U$ & $\alpha$ \\
\hline$\tau$ & $d$ & $N$ & $\sigma$ & $\rho$ & 2 & J & z \\
\hline$x$ & $\ltimes$ & $\rtimes$ & $x$ & 又 & z & $y$ & 8 \\
\hline 9 & $G$ & ( & $c$ & D & 6 & 0 & $\cup$ \\
\hline$\checkmark$ & a & $y$ & 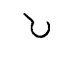 & 2 & $\Omega$ & $\sigma$ & $r$ \\
\hline$z$ & $\mu$ & ה & $\epsilon$ & Э & $\epsilon$ & $\tau$ & $\epsilon$ \\
\hline$e$ & $\gamma$ & Q & 9 & $\delta$ & $\nabla$ & $\Gamma$ & $\angle$ \\
\hline$r$ & $T$ & $b$ & $\checkmark$ & $\uparrow$ & -1 & r & L \\
\hline$\rho$ & $c_{0}$ & 9 & U & $\gamma$ & $\delta$ & م & $\delta$ \\
\hline$n$ & $y$ & \& & $x$ & v & $\mathscr{H}$ & $y$ & $\kappa$ \\
\hline
\end{tabular}


Two different random orders were used in respect of the order of presintation of the standard cards.

The subjects performed first the test of simultaneous presentation of letters. The order of the three remaining tests was varied randomly for each subject. The total number of errors made by the subjects in each of the two tasks was recorded.

\section{RESULTS}

Only one error was made in the simultaneous presentation of letters while there were 41 in the simultaneous presentation of forms, 20 of these errors being made by one child alone. Statistical comparison (Wilcoxon matched-pairs signed-rank test) between the results obtained in the tests of simultaneous presentation showed that the difference between the distribution of the scores was only marginally significant $(p<.05$, one-tailed test). On the other hand, there was a highly significant difference $(\mathrm{p}<.0001)$ between the results in the successive presentation of letters and forms. Thus, only 16 errors were made by four children in the successive presentation of letters compared with 266 errors in the successive presentation of forms, all but one child making errors in the latter task.

In order to establish whether there was an association between reading proficiency and ability to remember the spatial orientation of forms, a Spearman rank correlation was calculated between the scores obtained in the Schonell test (reading age) and those obtained in the test of successive presentation of forms. The rank correlation was +.08 , indicating no significant association between these two tests.

A further analysis was carried out of the types of errors made in the successive presentation of forms, and this analysis is shown in Table 1 . The number of errors appeared to be equally distributed among the different alternatives-except for the left-right reversal error which accounted for $43 \%$ of all errors. In order to establish whether a form was most frequently confused with its left-right reversal, an analysis of variance was performed. This revealed significant differences between the types of errors made by the subjects $(F=10.80 ; \mathrm{df}=6 / 203$; $\mathrm{p}<.001)$. Subsequent testing using the Scheffé (1953) method of post hoc comparisons showed that only the left-right reversal error contributed significantly to the overall $\mathrm{F}$.

\section{DISCUSSION}

This study shows that the ability of young readers to match the spatial orientation of forms is not significantly inferior to their accuracy in matching spatially confusable letters. On the other hand, their ability to remember the spatial orientation of forms is significantly inferior to their accuracy in remembering spatially confusable letters.

The results also indicate that there is no correlation between individual performances in the reading test and in the test of successive presentation of forms.

Analysis of the types of errors made in the successive presentation of forms indicates that the most prevalent error is that of confusing a form with its left-right reversal.

The observation that children between the ages of 10 and 11 years can adequately discriminate (i.e., see differences between) the spatial orientation of forms is not surprising in view of the observation of Gibson et al. (1962) of the development between the ages of 4 and 8 of the ability to discriminate visually a set of letter-like forms (i.e., forms constructed with the same constraints which govern the formation of printed capitals). One of the aspects they studied was the discrimination of a letter-like form from its rotations and reversals. It was found that the errors in discriminating orientation were higher in the young (that is the 4-year-old) group, but had declined to almost zero by the eighth year. This finding might be expected because directional orientation is not critical for identification of the different letter-like forms. It seems that between the seventh and eighth years children learn that orientation of letters is a factor relevant to their discrimination. The fact that the subjects in the present study performed accurately in discriminating the orientation of the forms-in spite of the fact that the forms used did not incorporate features found in actual letters-indicates that they have acquired a clear understanding that a change in spatial orientation is a cue for differentiation of identical forms. On the other hand, the large number of errors made in the successive presentation of forms indicates that memory for the orientation of nonfamiliar shapes remains insecure up to the age of 10-11 years in children with concordant reading ages. In this respect, it is pertinent to mention the study of Trieschmann (1968), who compared the ability of normal and retarded readers of similar age (7-8 years) in a test designed to remember letter-like forms (see above). The task in the Trieschmann study required the subjects to look at a card with a letter-like form drawn on it, for a 10-sec period, and then (after the card had been removed from view) to select out of 12 transformations one or more which were exactly the same as the standard. Out of the 12 transformations offered as possible choices, 5 were changes in orientation. The results show that the score obtained by the retarded readers was inferior to that of the normal readers for the task as a whole. However, perusal of Trieschmann's data shows that there were no significant differences between retarded and normal readers in respect to the number of errors made for rotations and reversals. These findings, in conjunction with the fact that there is no significant correlation between reading age and the performance on the successive presentation of forms, indicate that the ability to read is not necessarily accompanied by a concomitant ability to remember the orientation of nonfamiliar forms.

The salient finding in the present study is the differential difficulty in the recognition of spatially confusable letters as

Table, 1

Analysis of Errors Made in the Successive Presentation (Forms)

\begin{tabular}{|c|c|c|c|c|c|c|c|}
\hline & \multicolumn{2}{|c|}{ Rotation } & \multicolumn{3}{|c|}{ Reversal } & \multicolumn{2}{|c|}{ Distortion } \\
\hline & $\begin{array}{c}90 \mathrm{Deg} \\
\text { Left }\end{array}$ & $\begin{array}{c}90 \text { Deg } \\
\text { Right }\end{array}$ & $\begin{array}{l}\text { Left- } \\
\text { Right }\end{array}$ & $\begin{array}{c}\text { Up- } \\
\text { Down }\end{array}$ & $\begin{array}{l}\text { Up-Down/ } \\
\text { Left-Right }\end{array}$ & 1 & 2 \\
\hline $\begin{array}{l}\text { Total Number af Errors } \\
\text { Number of Children Makìng Errors } \\
\text { Mean Number of Errors }\end{array}$ & $\begin{array}{l}25 \\
13 \\
\quad .83 \\
\end{array}$ & $\begin{array}{l}27 \\
12 \\
\quad .90 \\
\end{array}$ & $\begin{array}{r}112 \\
24 \\
3.73 \\
\end{array}$ & $\begin{array}{l}34 \\
20 \\
1.13\end{array}$ & $\begin{array}{l}20 \\
11 \\
\quad .67\end{array}$ & $\begin{array}{l}26 \\
11 \\
\quad .87\end{array}$ & $\begin{array}{l}22 \\
14 \\
.73\end{array}$ \\
\hline
\end{tabular}


compared with that of nonfamiliar forms. It is, therefore, pertinent to consider the nature of the tasks, in order to establish the possible causes of such marked discrepancy.

Immediately after a brief exposure of an individual letter, the subjects have a relatively complete description of that experience, in that they possess a visual representation and a verbal code. However, the efficiency of the visual representation is known to decay $1.5 \mathrm{sec}$ after its exposure (Posner \& Keele, 1967), after which the subject will rely on the basis of the verbal code for an adequate identification. The large number of errors of identification in the successive presentation of forms might, therefore, be due to a short decay time of the visual representation and the absence of verbal rehearsal between presentation and recognition. A similar interpretation has been advanced by Holding (1972) in a study designed to compare the ability of adult subjects to reproduce an array of English and Arabic characters. Holding's study showed that, after a brief exposure $(50 \mathrm{msec})$ of an array of 12 English letters, the subject could reproduce adequately 3 to 4 letters; on the other hand, using the same procedure, the subjects who were not familiar with Arabic symbols were unable to reproduce reliably a single Arabic character. The results could not be explained on the basis of the complexity of the Arabic symbols, and Holding proposed that since the Arabic characters had no verbal equivalent for the English-speaking subjects their reproduction would be dependent mainly upon storage of the visual representation. Holding considers that the visual representation, contrary to widely accepted views (see Neisser, 1967; Sperling, 1960), is likely to be "processed" immediately after presentation rather than remaining in storage as a passive sensory trace.

The above observations, therefore, suggest that the memory processes involved in remembering the orientation of forms and those involved in remembering spatially confusable letters differ from each other. It is clear that the memory for the orientation of spatially confusable letters is dependent upon the close link that has been established between a phoneme and the specific spatial orientation of the related letter.

Another finding of interest in the present study relates to the high percentage of errors made by the subjects involving confusion of the standard with its left-right reversal. In this respect, it is important to note that recent studies (Sekuler \& Houlihan, 1968; Wolff, 1971) have shown that when adult subjects are required to classify pairs of horseshoe-shaped stimuli-presented in the horizontal plane-response time is longer for the left-right than for the up-down reversal pair. But the reason why a form is more frequently confused with its left-right reversal remains unclear, and further research is needed to elucidate this point.

The observations reported here suggest that learning the orientation of spatially confusable letters is a specific type of learning which is not necessarily accompanied by a concomitant ability to remember the spatial orientation of forms in general.

\section{REFERENCES}

Asso, D., \& Wyke, M. Discrimination of spatially confusable letters by young children. Journal of Experimental Child Psy chology, 1971, 11, 11-20.

Davidson, H. P. A Study of the confusing letters b, d, p, and q. Journal of Genetic Psy chology, 1935, 47, 458-467.

Dunn-Rankin, P. The similarity of lower case letters of the English alphabet. Journal of Verbal Learning and Verbal Behavior, 1968, 7, 990-995.

Fellows, B. J. The discrimination process and development. Oxford, England: Pergamon Press, 1968

Gibson, E. J., Gibson, J. J., Pick, A. D., \& Osser, H. A. A developmental study of the discrimination of letter-like forms. Journal of Comparative and Physiological Psychology, 1962, 55, 897-906.

Hildreth, $G$. The success of young children in number and letter construction. Child Development, 1932, 3, 1-14.

Holding, D. $H$. Brief visual memory for English and Arabic letters. Psy chonomic Science, 1972, 28, 241-242.

Ilg, F. L., \& Ames, L. B. Developmental trends in reading F. L., \& Ames,

Lovell, L., Shapton, D., \& Warren, N. S. A study of some cognitive and other disabilities in backward readers of average intelligence as assessed by a non-verbal test. British Journal of Educational Psychology, 1964, 34, 58-64.

Lyle, J. G. Reading retardation and reversal tendency: a factorial study. Child Development, 1969, 40, 833-843.

Neisser, U. Cognitive psychology. New York: Appleton-Century-Crofts, 1967.

Posner, M. I., \& Keele, S. W. Decay of visual information from a single letter. Science, 1967, 158, 137-139.

Scheffé, H. A method for judging all contrasts in the analysis of variance. Biometrika, 1953, 40, 87-104.

Schonell, F. J., \& Schonell, F. E. Diagnostic and attainment testing. Edinburgh and London: Oliver \& Boyd, 1956.

Sekuler, R. W., \& Houlih an, K. Discrimination of mirror-images: choice time analysis of human adult performance. Quarterly choice time analysis of human adult performance. Qu

Shepherd, E. M. Reading efficiency of 809 average school children. American Journal of Ophthalmology, 1956, 41, 1029-1039.

Sperling, G. The information available in brief visual G. The information available in brief
presentations. Psychological Monographs, 1960, 74, 11, Whole No. 498.

Trieschmann, R. B. Undifferentiated handedness and perceptual development in children with reading problems. Perceptual and Motor Skills, 1968, 27, 1123-1134.

Vernon, M. D. Backwardness in reading. Cambridge, England: Cambridge University Press, 1957.

Wechsler, D., \& Hagin, R. A. The problem of axial rotation in reading disability. Perceptual and Motor Skills, 1964, 19, 319-326.

Wilson, F. T., \& Fleming, C. W. Reversals in reading and writing. Journal of Genetic Psy chology, 1938, 53, 3-31.

Wolff, P. Mirror-image confusability in adults. Journal of Experimental Psy chology, 1971, 91, No. 2, 268-272.

(Received for publication December $5,1974$. 